\title{
COLONIZAÇÃO RADICULAR DE PLANTAS CULTIVADAS POR Ralstonia solanacearum BIOVARES 1, 2 E 3
}

\author{
José Magno Martins Bringel ${ }^{1 *}$; Armando Takatsu²; Carlos H. Uesugi ${ }^{3}$ \\ ${ }^{1}$ Depto. de Entomologia, Fitopatologia e Zoologia - USP/ESALQ, C.P. 9 - CEP: 13418-900 - Piracicaba, SP. \\ ${ }_{3}^{2}$ Instituto de Ciências Agrárias - UFU, Campus Umuarama, Bloco - 2E - CEP: 38400-902 - Uberlândia, MG. \\ ${ }^{3}$ Depto. de Fitopatologia - UnB - CEP: 70910-900 - Brasília, DF. \\ *Autor correspondente <jmmbring@carpa.ciagri.usp.br>
}

\begin{abstract}
RESUMO: A murcha bacteriana causada por Ralstonia solanacearum é considerada a principal doença de origem bacteriana no mundo. Centenas de espécies de plantas pertencentes a mais de 50 famílias botânicas têm sido relatadas como hospedeiras. Foi avaliada, em condições de casa de vegetação, a colonização radicular de alface, arroz, cebolinha, ervilha, pepino e soja, por seis isolados de Ralstonia solanacearum (Rs), biovares 1, 2 e 3. Estirpes dos isolados de Rs com resistência múltipla aos antibióticos estreptomicina, rifampicina e cloranfenicol foram utilizadas. A colonização foi avaliada 45 dias após a inoculação, através do plaqueamento de suspensão de trituração em meio de cultura semi-seletivo. A ervilha comportou-se como hospedeira de todos os isolados mas, apenas um isolado da biovar 3 foi patogênico a esta espécie. A soja apresentou populações elevadas de quatro isolados distribuídos entre as três biovares e o pepino, de apenas dois isolados das biovares 1 e 3 . Exceto para o isolado que foi patogênico à ervilha, as plantas não apresentaram sintomas da doença, comportando-se como hospedeiras não suscetível. O arroz apresentou populações muito baixas de todos os isolados. Alface e cebolinha não hospedaram nenhum dos isolados inoculados. Os resultados mostram a capacidade de Rs colonizar e sobreviver em diferentes espécies de plantas como rizobactérias.
\end{abstract}

Palavras-chave: murcha bacteriana, ecologia

\section{ROOT COLONIZATION OF CULTIVATED PLANTS INOCULATED WITH Ralstonia solanacearum BIOVAR 1, 2 AND 3}

\begin{abstract}
Bacterial wilt caused by Ralstonia solanacearum is considered the main plant disease of bacterial origin in the world, where hundreds of plant species in more than 50 botanical families are host plants. Root colonization of lettuce (Lactuca sativa), rice (Oryza sativa), spring onion (Allium fistulosum), pea (Pisum sativum), cucumber (Cucumis sativus), and soybean (Glycine max) by six isolates of Ralstonia solanacearum (Rs) biovars 1, 2 and 3 was evaluated under greenhouse conditions. Bacterial strains resistant to streptomycin, rifampicin and chloranfenicol were used. Root colonization was evaluated 45 days after inoculation by counting bacteria in root extracts of culture media with antibiotics. Pea plants hosted all six isolates, but only the isolate biovar 3 was pathogenic to this species. High populations of four isolates of the three biovars were found on soybean, and cucumber hosted high population of only two isolates (biovars 1 and 3). Pea was a non-susceptible host for Rs, except for one pathogenic isolate. Rice hosted very low populations of all isolates, while lettuce and spring onion did not host any isolates. These results showed the ability of Rs to colonize and survive on different plant roots as rhizobacteria.
\end{abstract}

Key words: bacterial wilt, ecology

\section{INTRODUÇÃO}

A murcha bacteriana causada por Ralstonia solanacearum (Smith 1896) comb. nov. Yabuuchi et al. (1995) (Rs) é considerada uma das mais importantes e prejudiciais doenças bacterianas de plantas, em especial nas regiões tropicais. No Brasil, as culturas mais afetadas estão entre as solanáceas, como batata, tomate, pimentão, berinjela e jiló, mas inclui também a bananeira. A doença é um grande fator de risco para a produção da batata em áreas onde ela é cultivada (Lopes, 1994). Já nas demais solanáceas, a doença tem grande incidência e severidade nas regiões tropicais de baixa altitude como na Amazônia e regiões baixas do Nordeste e do Centro Oeste (Lopes \& Takatsu, 1997).

Apesar de grande número de dados terem sido obtidos nos últimos anos em estudos sobre esta doença, especialmente na área de caracterização quimiotaxonômica e molecular do patógeno, poucos avanços foram registrados em relação a sua epidemiologia, não sendo ainda possível estabelecer estratégias adequadas e seguras de controle. Esta situação deve-se a inúmeros fatores, sendo os mais importantes a grande variabilidade do patógeno quanto à virulência, à preferência de hospedeiras, à adaptação às condições edafoclimáticas e a existência de centenas de espécies hospedeiras sintomáticas e assintomáticas entre as plantas cultivadas, nativas e invasoras (Hayward, 1991).

Diante desta situação, recomenda-se atualmente um conjunto de medidas integradas de controle (Hayward, 1986). Dentro desta estratégia, a rotação de 
culturas e a eliminação de plantas capazes de manter a população de Rs por longo tempo nas áreas infestadas são consideradas como as medidas mais importantes, por ser Rs um patógeno que tem baixa capacidade de sobrevivência no solo e porque sua persistência nas áreas infestadas se deve à associação com raízes de plantas na forma de infecção sistêmica ou epifítica (Melo, 1995; Viana, 1995).

O conhecimento da reação das espécies cultivadas como hospedeiras ou não de diferentes estirpes de Rs encontradas na região ou área de cultivo é uma condição fundamental para que se possa utilizar cultura adequada para a rotação. Entretanto, pouco se sabe sobre a sobrevivência de diferentes isolados deste patógeno em função das diferentes espécies cultivadas e invasoras (Takatsu et al., 1984).

O presente estudo teve como objetivo avaliar, em condições de casa-de-vegetação, a colonização radicular de Rs em alface (Lactuca sativa), arroz (Oryza sativa), cebolinha (Allium fistulosum), ervilha (Pisum sativum), pepino (Cucumis sativus) e soja (Glycine max).

\section{MATERIAL E MÉTODOS}

Foram utilizados seis os isolados de Rs, das biovares 1,2 e 3, selecionadas com resistência aos antibióticos estreptomicina, rifampicina e cloranfenicol (TABELA 1). Esses isolados foram obtidos utilizando-se as técnicas descritas por Melo (1995), a partir de isolados de Rs provenientes da coleção de Bactérias Fitopatogênicas da Universidade de Brasília - UnB e da Embrapa Hortaliças, Brasília - DF, e identificadas ao nível de biovar, de acordo com a classificação de Hayward (1964).

As plantas testadas foram alface cv. Lisa; arroz cv. BR-201, cebolinha cv. Todo Ano AG-558; ervilha cv. Torta de Flor Roxa; pepino cv. Salada Agroceres e soja cv. FT-104.

Cada uma dessas plantas foi inoculada separadamente com os seis isolados de Rs resistentes aos antibióticos, sendo duas variantes de cada biovar, vertendo-se $100 \mathrm{ml}$ da suspensão bacteriana ajustada à concentração de $1 \times 10^{8}$ ufc $\mathrm{mL}^{-1}$, por vaso, aos vinte dias após a germinação. As parcelas testemunhas receberam apenas $100 \mathrm{ml}$ de água esterilizada por vaso. O substrato utilizado foi composto de solo peneirado, adubado e autoclavado a $1 \mathrm{~atm}$ de vapor por duas horas. A avaliação foi feita em função do tempo decorrido até que todas as plantas inoculadas apresentassem sintomas.

O delineamento experimental foi 0 de blocos casualizados, com 42 tratamentos (6 isolados +1 testemunha x 6 espécies de plantas) e 4 repetições, sendo cada parcela composta por 5 vasos. Foram mantidas 4 plantas por vaso em parcelas de alface, pepino, ervilha e soja e 20 a 25 plantas nas parcelas de cebolinha e arroz.
A coleta de raízes foi feita 45 dias após a inoculação em todos os vasos da parcela, aproveitandose somente as raízes finas terminais. Estas foram lavadas cuidadosamente para retirar o excesso de terra, enxugadas em toalhas de papel, desinfetadas superficialmente (álcool 70\%) e separadas em amostras de $10 \mathrm{~g}$ por parcela. Essas amostras foram trituradas em almofariz, diluídas em volume final de $100 \mathrm{ml}$ e alíquotas de $0,05 \mathrm{ml}$ do extrato foram plaqueadas em meio 523 (Kado \& Heskett, 1970) contendo os antibióticos e fungicidas, com 5 repetições. Os antibióticos utilizados foram: estreptomicina na concentração final de $50 \mathrm{ug} \mathrm{L}^{-1}$, rifampicina $50 \mathrm{ug} \mathrm{L}^{-1}$, cloranfenicol $10 \mathrm{ug} \mathrm{L}^{-1}$ e os fungicidas benomyl $50 \mathrm{ug} \mathrm{L}^{-1}$ e chlorothalonil $50 \mathrm{ug} \mathrm{L}^{-1}$. As placas foram incubadas a $30^{\circ} \mathrm{C}$ e as colônias brancas, brilhantes e fluídas que se formaram entre 48 e 72 horas de incubação foram contadas, através do contador de colônias, em um período de 3 a 5 dias.

Os dados foram analisados através do programa Statistical Analysis System - SAS. Para efeito de análise estatística os dados foram transformados em log $(x+1)$ para normalizar a variável. As médias dos tratamentos foram comparadas pelo teste de Tukey, a $1 \%$.

\section{RESULTADOS E DISCUSSÃO}

Dentre as seis espécies de plantas avaliadas neste trabalho, ervilha, soja e pepino apresentaram populações elevadas da maioria dos isolados do patógeno em comparação às populações encontradas em arroz, alface e cebolinha (TABELA 1). Nas plantas de alface e cebolinha foram detectadas baixas populações de Rs no sistema radicular. Não existe nenhum relato que alface e cebolinha sejam hospedeiras, o que as indicaria como boas opções para rotação de culturas em áreas infestadas. No entanto, estes resultados necessitam ser confirmados, em ensaios sob condições de campo.

O arroz apresentou populações muito baixas de todos os isolados (TABELA 1). Viana (1995) considerou o arroz como uma espécie não hospedeira quando estudou o comportamento da flutuação populacional de Rs em diferentes idades após a inoculação. Estes dados estão também de acordo com Quimio \& Chan (1979), que indicam esta espécie como uma das melhores opções para a rotação de culturas em solos infestados.

Considerando a população de Rs encontrada em arroz como parâmetro de uma planta considerada não hospedeira, a ervilha mostrou ser hospedeira de todos os isolados de Rs das três biovares testadas neste trabalho, entretanto, com populações significativamente diferentes entre os isolados (TABELA 1). Mostrou ser, também, suscetível ao isolado UnB-630 da biovar 3 , apresentando a mais alta população nas raízes, com amarelecimento generalizado das plantas e crestamento das partes terminais das folhas. Esta observação vem reforçar os relatos de que a ervilha é hospedeira 
TABELA 1 - População de estirpes resistentes a estreptomicina, rifampicina e cloranfenicol de isolados de Ralstonia solanacearum, biovares 1,2 e 3 em raízes de espécies de plantas cultivadas.

\begin{tabular}{|c|c|c|c|c|c|c|}
\hline ESPÉCIE & $\begin{array}{c}\text { UnB-1033 } \\
\text { Bv. } 1\end{array}$ & $\begin{array}{c}\text { UnB-1103 } \\
\text { Bv. } 1\end{array}$ & $\begin{array}{c}\text { UnB-964 } \\
\text { Bv. } 2\end{array}$ & $\begin{array}{c}\text { CNPH-121 } \\
\text { Bv. } 2\end{array}$ & $\begin{array}{c}\text { UnB-630 } \\
\text { Bv. } 3\end{array}$ & $\begin{array}{c}\text { UnB-1102 } \\
\text { Bv. } 3\end{array}$ \\
\hline & \multicolumn{6}{|c|}{1000 ufc g${ }^{1}$ de raízes } \\
\hline Ervilha & $2069 a{ }^{*} C D^{*}$ & 1897 a D & 2720 a BC & 2911 a $A B$ & 3492 a $A$ & 2659 a BC \\
\hline Soja & 1941 a $A B$ & 2481 a A & 2029 b AB & 1545 b B & 778 b C & $2331 \mathrm{ab} A$ \\
\hline Pepino & 2593 a $A B$ & $973 \mathrm{~b} D$ & $1875 \mathrm{bC}$ & $580 \mathrm{c} \mathrm{D}$ & 2973 a A & 1912 a BC \\
\hline Arroz & $147 \mathrm{~b} \quad \mathrm{~A}$ & $88 \mathrm{c} \mathrm{A}$ & $104 \mathrm{c} \mathrm{A}$ & 119 c A & 148 b A & 131 c A \\
\hline Alface & $4 \mathrm{CA}$ & $4 \mathrm{~d} \mathrm{~A}$ & $3 \mathrm{~d} A$ & $4 \mathrm{~d} \mathrm{~A}$ & $1 \mathrm{cA}$ & $4 \mathrm{~d} \mathrm{~A}$ \\
\hline Cebolinha & $2 \mathrm{c} \mathrm{A}$ & $3 \mathrm{~d} A$ & $4 \mathrm{~d} \mathrm{~A}$ & $3 \mathrm{~d} A$ & $2 \mathrm{cA}$ & $1 \mathrm{~d} A$ \\
\hline
\end{tabular}

*Valores seguidos da mesma letra minúscula nas colunas e mesma letra maiúscula nas linhas não diferem estatisticamente pelo teste de Tukey a $1 \%$.

suscetível de Rs (Bradbury, 1986). Entretanto, os dados obtidos indicam que esta cultura atua, para a maioria dos isolados de Rs, como "hospedeira não suscetível", termo este utilizado por Viana (1995), para a planta que tem a qualidade de hospedar a bactéria considerada patógeno, mas sem apresentar nenhum sintoma da doença. Esta condição é reforçada pelo fato de ser rara a constatação da ocorrência de murcha bacteriana nesta espécie.

A soja não é relatada na literatura como hospedeira de Rs. Entretanto, no presente trabalho apresentou populações significativamente mais elevadas de quatro isolados (UnB-1033 e UnB-1103 da biovar 1, UnB-964 da biovar 2 e UnB-1102 da biovar 3). Somente, a população do UnB 630 (biovar 3) não diferiu estatisticamente da população de arroz (TABELA 1). Estes dados constituem uma indicação de que a soja pode funcionar como hospedeira dos isolados que colonizam bem suas raízes.

Parente et al. (1990) constataram a ocorrência de murcha severa em cultura de pepino na região de Manaus, $\mathrm{AM}$ e verificaram que isolados das biovares 1 e 3 podem infectar e causar murcha nesta espécie. No presente trabalho, o pepino apresentou populações significativamente mais elevadas dos isolados UnB-630 (biovar 3) e UnB-1033 (biovar 1), causando senescência precoce, com amarelecimento e crestamento terminal das folhas, sem contudo causar sintomas típicos da murcha. Apenas a população do isolado $\mathrm{CNPH}-121$ da biovar 2 não diferiu estatisticamente da população deste mesmo isolado verificada na cultura do arroz (TABELA 1). Estes resultados indicam que o pepino pode atuar, para a maioria dos isolados de Rs, como hospedeira não suscetível.

Comparando-se os resultados obtidos em ervilha, soja e pepino (TABELA 1), pode-se visualizar melhor as variações que ocorrem quanto à preferência de hospedeiras entre os isolados de Rs, mesmo dentro da mesma biovar. Estes resultados indicam que a maioria das isolados de Rs podem colonizar e sobreviver em diferentes espécies de plantas como rizobactérias, conforme também observado por Melo (1995) e Viana (1995).
Estas informações vêm reforçar a necessidade de se fazer a identificação das plantas hospedeiras suscetíveis ou não para estabelecer estratégias de controle da murcha bacteriana com rotação de culturas, a nível regional, em função dos isolados locais (Lopes \& Takatsu, 1997). Pepino e soja poderão ser boas opções para rotação desde que não sejam hospedeiros dos isolados do patógeno existentes na área, necessitando a determinação da biovar previamente.

Os dados obtidos sob condições de casa de vegetação somente poderão ser considerados definitivamente válidos após a comprovação em condições de campo. Esta comprovação poderá ser buscada gradativamente, em diferentes áreas e regiões, quando for possível executar ensaios em solos naturalmente infestados, pois não se pode criar campos experimentais abertos infestados com isolados e biovares obtidos de diferentes regiões (Lopes \& Takatsu, 1997).

Como a comprovação nas condições naturais de campo é baseada na manifestação da doença, a avaliação não pode ser feita com a mesma variedade ou espécie indicadora, mas sim com a variedade ou espécie suscetível compatível com o isolado do patógeno presente na área infestada, o que dificulta muito a comparação dos dados obtidos em diferentes ensaios. Além deste problema, fatores como temperatura, textura do solo, regime de chuva, composição microbiana do solo e muitos outros interferem marcadamente na manifestação da doença o que dificulta ainda mais a comparação dos dados, mesmo repetindo-se os ensaios por vários anos consecutivos (Saile \& Denny, 1995).

Assim sendo, o aperfeiçoamento de métodos de avaliação da colonização e da flutuação populacional de Rs em raízes de plantas sob condições de casa-devegetação é fundamental para que a grande maioria dos ensaios necessários para a obtenção de informações sobre a sobrevivência de diferentes isolados de Rs em diferentes espécies e variedades de plantas. 


\section{REFERÊNCIAS BIBLIOGRÁFICAS}

BRADBURY, J.F. Guide to plant pathogenic bacteria. Kew: International Mycological Institute, 1986. 332p.

HAYWARD, A.C. Bacterial wilt caused by Pseudomonas solanacearum in Asia and Australia: an overview. In: PERSLEY, G.J. (Ed.) Bacterial wilt disease in Asia and South Pacific. Camberra: Australia Center for International Resemch 1986. p.15-24. (ACIAR Proceedings, 13)

HAYWARD, A.C. Biology and epidemiology of bacterial wilt caused by Pseudomonas solanacearum. Annual Review of Phytopathology, v.29, p.65-87, 1991.

HAYWARD, A.C. Characteristics of Pseudomonas solanacerum. Journal of Applied Bacteriology, v.27, p.265-277, 1964.

KADO, C.L.; HESKETT, M.G. Selective media for isolation of Agrobacterium, Corynebacterium, Erwinia, Pseudomonas and Xanthomonas. Phytopathology, v.60, p.969-976, 1970.

LOPES, C.A. Situação da murcha bacteriana da batata no Brasil. In: TALLER SOBRE ENFERMIDADES BACTERIANAS DE LA PAPA, Brasília, 1993. Memórias. Lima: CIP; EMBRAPA, CNPH, 1994. p.7-9.

LOPES, C.A.; TAKATSU, A. Controle da murcha bacteriana. Fitopatologia Brasileira, v.22, p.224-225, 1997.

MELO, M.S. de. Avaliação de plantas cultivadas como hospedeiras de Pseudomonas solanacearum em condições de casa-de-vegetação. Brasília, 1995. 60p. Dissertação (Mestrado) - Universidade de Brasília.

PARENTE, P.M.G.; TAKATSU, A; LOPES, C.A. Virulência de isolados de Pseudomonas solanacearum de pepino a algumas solanáceas e susceptibilidade de pepino ao patógeno de diferentes hospedeiras. Fitopatologia Brasileira, v.15, p.3135, 1990.
QUIMIO, A.J.; CHAN, H.H. Survival of Pseudomonas solanacearum E. F. in the rhizosphere of some weeds and economic plant species. Philippine Phytopathology, v.15, p.108-121, 1979.

SAILE, E.; DENNY T.P. Invasion and colonization of tomato seedlings by Pseudomonas solanacearum. Phytopathology, v.85, p.1121, 1995

TAKATSU, A.; SILVA, C.B. ; REIFSCHNEIDER. F.J.B. Variabilidade e distribuição de Pseudomonas solanacearum de solanáceas cultivadas nas diferentes regiões do Brasil. Fitopatologia Brasileira, v.9, p.387, 1984.

VIANA, E.C.G.M. Estudos da sobrevivência de um isolado variante de Pseudomonas solanacearum em raízes de plantas cultivadas. Brasília, 1995, 61p. Dissertação (Mestrado) Universidade de Brasília.

YABUUCHI, E.; KOSAKO, Y.; YANO, I.; HOTTA, H.; NISHIUCHI, Y. Transfer of two Burkholderia and Alkaligenes species to Ralstonia gen. nov.: proposal of Ralstonia picketii (Ralston, Palleroni and Doudoroff, 1973) comb. nov., Ralstonia solanacearum (Smith,1869) comb. nov. and Ralstonia eutropha (Davis, 1969) comb. nov. Microbiology and Immunology, v.39, p.897-904, 1995.

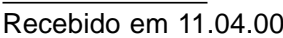

